\title{
Making a market for on-farm food loss: Exploring food banks as a market for Southeastern produce
}

\author{
Rebecca Dunning, ${ }^{\text {* J J. Dara Bloom, }}{ }^{\mathrm{b}}$ Emma Brinkmeyer ${ }^{\mathrm{b}}$ \\ North Carolina State University
}

Submitted May 30, 2019 / Revised September 6, 2019 / Accepted September 8, 2019 /

Published online February 18, 2020

Citation: Dunning, R., Bloom, J. D., \& Brinkmeyer, E. (2020). Making a market for on-farm food loss:

Exploring food banks as a market for Southeastern produce. Journal of Agriculture, Food Systems, and

Community Development, 9(2), 185-195. https://doi.org/10.5304/jafscd.2020.092.014

Copyright (C) 2020 by the Authors. Published by the Lyson Center for Civic Agriculture and Food Systems. Open access under CC-BY license.

\begin{abstract}
Reducing food waste across the supply chain is one means to more efficiently utilize natural resources and potentially divert unutilized food to the foodinsecure. Food banks are the primary institution by which this transfer occurs in the U.S. Over the past 20 years, growth in the number of pounds distributed annually by food banks has been accompanied by a focus on the nutritional quality of the food distributed. This shift has included an increase in sourcing of fresh produce directly from growers, with anecdotal evidence that some food banks have market-based relationships in which food banks pay growers and even forward contract for
\end{abstract}

a * Corresponding author: Rebecca Dunning, Department of Horticultural Sciences, North Carolina State University; 2721 Founders Drive; Raleigh, NC 27607 USA; rebecca_dunning@ncsu.edu

b J. Dara Bloom and Emma Brinkmeyer, Department of Agricultural and Human Sciences, North Carolina State University. product. The current study sought to examine the prevalence of these relationships for the purpose of evaluating food banks as a market channel for farmers' surplus and cosmetically imperfect produce. The authors collected data on market relationships between food banks and produce farmers through interviews with food bank operators in 13 southeastern U.S. states. Based on interviews with 24 individuals representing 16 food banks, food bank associations, and regional nonprofit produce distributors serving food banks, we find payments from food banks to farms to be a widespread practice. Eleven of the 13 states (and 14 of the 16 food banks) reported paying growers either directly or via Feeding America's online Produce Matchmaker system. Interviews also revealed sourcing manag-

\section{Funding Disclosure}

This material is based upon work supported by the National Institute of Food and Agriculture, U.S. Department of Agriculture, under award number 571385-02452 through the Southern Sustainable Agriculture Research and Education program. 
ers' expectations that compensating growers could be a "win-win" strategy for both food banks and growers. Such practices are supported by infrastructure commitments from Feeding America, a network of food banks and pantries which includes $80 \%$ of food banks in the U.S.

\section{Keywords}

Farms, Food Banks, Food Waste, Surplus, Produce

\section{Introduction}

News accounts of the hardships experienced by families during the five-week U.S. federal government shutdown in early 2019 was a reminder both of the tenuousness of American families' ability to weather missed paychecks and the capacity of the food bank system to respond to these hardships (Elejalde-Ruiz, 2019; Simon, 2019). Food banks aggregate and distribute mainly donated foodstuffs to an estimated $60,000+$ community partner organizations, serving one in seven Americans in any given year, and often for extended periods of time (Campbell, Webb, Ross, Crawford, Hudson, \& Hecht, 2015; Poppendieck, 1999). Along with the growth in food banks' distributional capacity, there has been an increased emphasis on leveraging their connections to communities and families to enhance individual health (Campbell et al., 2015). One outcome is an increased distribution of fresh fruits and vegetables. Fresh produce comprised $43 \%$ of the total pounds of rescued food distributed in 2017 by Feeding America, the largest network of food banks and pantries in the U.S. (Feeding America, 2018).

The current study was motivated by this food bank sourcing trend and the authors' work to minimize on-farm produce loss in ways that economically benefit growers (Dunning, Johnson, \& Boys, 2019; Johnson et al., 2019; Johnson, Dunning, Bloom et al., 2018; Johnson, Dunning, Gunter et al., 2018), and by anecdotal and published evidence that food banks are compensating growers for produce (Vitiello, Grisso, Whiteside, \& Fischman, 2015). Farmers have long had the option of donating product to food banks, and occasional compensation to farmers for transportation costs is not unusual. However, the possibility that compensation is occurring on a consistent basis across numerous food banks could indicate the creation of a reliable market channel for farmers' surplus and cosmetically imperfect products.

Goals of this exploratory study were two-fold: (1) to gauge the prevalence of payments by food banks to produce growers across the southern region of the U.S, including the sources of funding used for these payments, and (2) to gain an understanding of food bank staff experiences and perceptions with regard to current and future directsourcing from farmers. Researchers sought to understand how, why, and to what extent food banks are shifting to include cash purchase of, and forward contracting for, produce purchased directly from farmers, and to collect estimates of the per-pound costs paid by food banks. The motivation for the study was to identify potential "winwin" strategies that could reduce on-farm produce loss and enhance farmers' profitability while providing food banks and their clients healthy, fresh food.

\section{Background}

\section{Food Banks}

The emergency food system arose from the desire to rescue wasted food and distribute it to people not adequately supported by publicly funded social programs (Poppendiek, 1999). The system originated in the 1960s under the mantel of Second Harvest, which was later largely absorbed into Feeding America. Since that time, a network of food banks has developed around the country with sophisticated warehouses and distribution systems, institutionalizing a system that was originally envisioned to serve people on only an "emergency" basis (Poppendieck, 1999). Food pantries and charitable feeding organizations experienced particularly rapid growth in the 1980s in response to cuts in federal social spending (Campbell et al., 2015; Poppendieck, 1999).

"Food banks," understood as entities that aggregate and distribute food to partnering entities, most often local "food pantries" managed by community-based organizations that distribute food directly to community members, exist in various sizes and are connected in various ways across the U.S. Feeding America, a network whose members 
make up $80 \%$ of U.S. food banks, negotiates arrangements with large retailers, manufacturers, and growers. Member food banks access these donations through the online Feeding America Choice System. This software platform is used by food banks to order donated food, which is apportioned to food banks based on the pounds of inventory they distribute annually and the prevalence of poverty in their geographic service area (Campbell et al., 2015). The Feeding America system is also the primary distributor of the U.S. Department of Agriculture's (USDA) Emergency Food Assistance Program (TEFAP) and Commodity Supplemental Food Programs. Individual food banks can also accept donations from local donors, purchase products, or work with other providers.

The types of food sourced and distributed by food banks have changed over time. An increase in food banks' sourcing and distribution of fresh produce reflects current public interest in and policies attending to the importance of fresh fruit and vegetables for dietary health, as well as the developing

\section{Figure 1. Sources of Fresh Produce for Food Banks and Clients}

Farms, aggregator/distributors, and retailers can donate or sell produce directly to community organizations for distribution to clients. More often, these donations are managed by regional food banks with the capacity to receive, hold, and distribute perishable items.

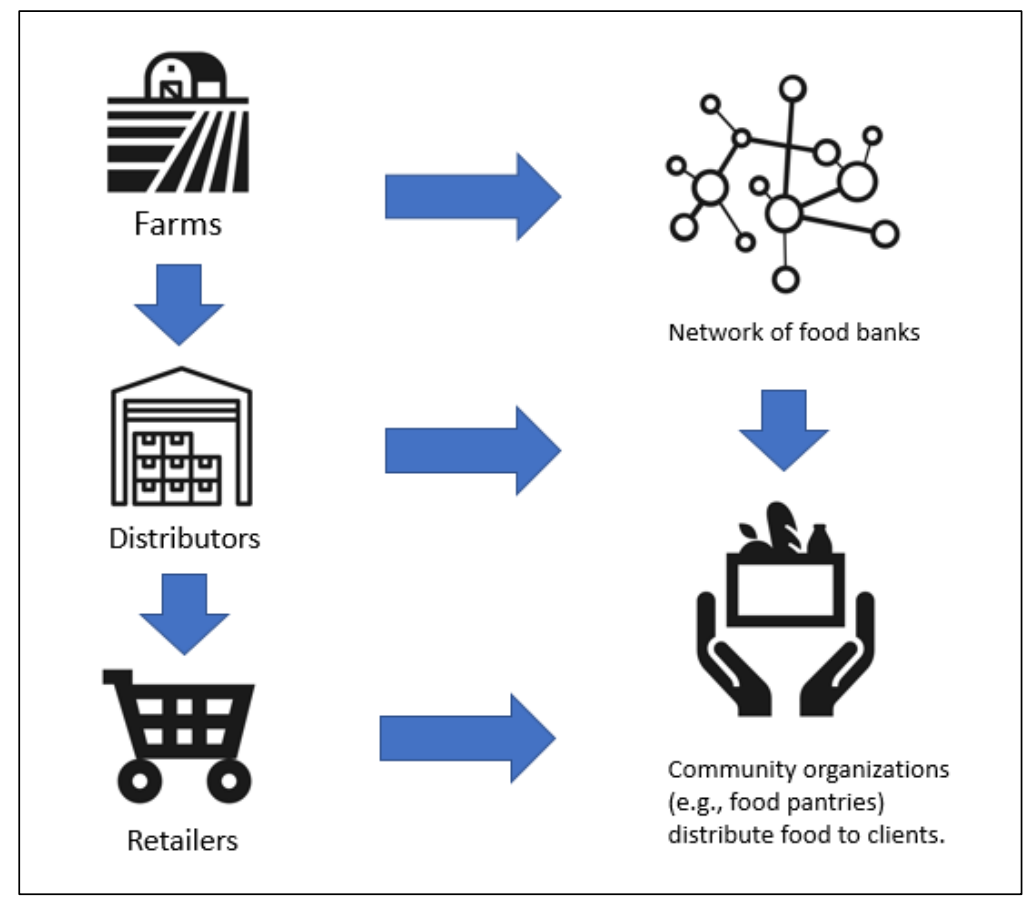

capacity of food banks and their client agencies (e.g., local food pantries) to store perishable products (Bazerghi, McKay \& Dunn, 2016; Campbell, Ross, \& Webb, 2013; Campbell et al., 2015; Shimada, Ross, Campbell \& Webb, 2013). Combined with declines in donations from grocery retailers, food banks are reportedly sourcing larger volumes and a greater variety of fresh produce directly from growers, with some reports of reimbursements to growers to cover their costs of harvest (Vitiello et al., 2015). A schematic of the sources and destinations for fresh produce in the food bank system is illustrated in Figure 1.

Feeding America's leadership and investment in infrastructural capacity are further supporting the move to more fresh produce. Produce Matchmaker, an online platform paralleling the Choice System, is designed specifically for fresh produce and allows food banks to work directly with growers to arrange shipments across the country according to their needs. The platform lists costs and shipping fees and includes anticipated product availability. For example, an apple grower or wholesaler can indicate loads of surplus product anticipated for the coming season.

In 2015, Feeding America took the major step of establishing six regional produce aggregation and distribution hubs (Feeding America, 2017). Two of these are located in the study region: The Southeast Regional Cooperative in Atlanta sources and distributes across seven states to 32 food bank members, and the Collaborative for Fresh Produce in Texas distributes across five states.

\section{Food Loss on Produce Farms}

Produce farmers can leave large amounts of product unharvested in the field for a number of reasons, including low market demand, harvest costs that outstrip estimated returns, and harvest labor needed elsewhere on the farm. Recent loss measurements for eight commonly grown southeastern crops find that a volume 
equal to $42 \%$ of sold produce remains in the field after the final harvest (Johnson, Dunning, Gunter et al., 2018). Of this in-field loss, half of the product met the same market standards for which the marketable portion had been sold, with the remaining half considered as good condition and edible but not meeting marketing specifications.

Farmers may donate to food banks, and legislation encourages donations using limited tax deductions and liability protection. While published research is not available to link the tax deduction benefit to farmers' likelihood of donation, a set of interviews with 17 midscale (median size of 1,027 acres [416 hectares] in production) produce growers in North Carolina found that growers did not view tax deductions as a benefit significant enough to justify going back into a field for an additional harvest (L. Johnson, personal communication, December 15, 2018). Growers indicated that their most likely reason for donation would be a rejected load and that the donation would take place at the point of the rejection, such as at a regional grocery distribution warehouse.

The majority of costs on a produce farm are associated not with production, but rather with the labor and packaging costs needed to transform product in the field into a saleable item. Food banks may cover "pick and pack-out costs" (PPO), payments to growers that offset the costs of harvesting and preparing product for transport to food banks. This can make it worthwhile for growers to return their own skilled harvest crews to the field for an additional harvest. Economic analysis using the volumes reported in the Johnson, Dunning, Gunter et al. study (2018) calculated that an estimated US $\$ 0.10 /$ pound PPO rate (based on PPO reports from North Carolina) for some crops could justify the costs of returning to conduct an additional harvest (Dunning et al., 2019).

Growers may not need to make a profit over and above covering their PPO cost in order to justify returning to the field. If growers have contracted labor with hourly requirements for each week, growers may harvest a field, even with the expectation of low yield, if the harvest crew is not needed elsewhere (Johnson \& Dunning, 2020). Even for growers who pay per unit harvested (e.g., pound, bucket), a grower may continue a low- yielding harvest to keep workers from seeking employment elsewhere (Johnson \& Dunning, 2020).

The current study sought to understand whether anecdotal reports of food banks reimbursing growers for PPO costs is a widespread practice. Prior findings on the sheer volume of produce that remains in farmers' fields, and the economic value of this loss, support the conjecture that the practice could simultaneously benefit growers, reduce farmlevel loss, and increase the availability of nutritionally dense foods for food banks and their clients. Common use of the practice would indicate its acceptance as a purchasing channel for the emergency food system and as a steady market for farmers' surplus product. "Steady" is the operative word. If farmers know that a reliable channel exists, it becomes something around which they can plan and establish an ongoing business relationship. The current study of food bank PPO practices in the southeast informs this potential win-win strategy for food banks, their clients, and farmers.

\section{Methods}

A 13-state area (Alabama, Arkansas, Florida, Georgia, Kentucky, Louisiana, Mississippi, North Carolina, Oklahoma, South Carolina, Tennessee, Texas, Virginia) was selected based on the regional focus of the study's funder and resource constraints. The members of the research team created a list of interview questions based on their experiences researching issues of on-farm food losses. These questions were designed to gain a better understanding of food banks' motivation to pay for produce, funding sources, and amount paid to farmers. We piloted the interview guide with one food resource manager at a North Carolina food bank in order to determine whether the questions, as worded, elicited responses that helped us answer our research questions. We also asked this interviewee for feedback on the types of questions asked as well as terminology used, and we made suggested edits. This revised interview guide and research plan underwent institutional review board (IRB) review and received an exempted status.

Researchers used web searches to identify any food bank networks or large food banks in each of 
the target states. This identification began with Feeding America's online food bank member directory, subsequent web searches, and snowball sampling, whereby interviewees were asked to identify other large food banks in their state. As an exploratory study, the goal was to understand the existence and extent of purchasing by the largest food banks in the state, rather than an exhaustive accounting of all food banks within and outside of the Feeding America network. In most cases, states were identified as having one large Feeding America network food bank that serviced numerous community organizations, and so we focused our efforts on contacting these food banks. Identified food banks were contacted by email and telephone to request an interview with the staff member most familiar with the practice of sourcing fresh produce directly from growers. In nearly all cases, the interviewees held a title indicating that they were the director of sourcing or a sourcing specialist. All the food bank staff members contacted agreed to be interviewed.

A total of 24 interviews were conducted. The final sample included 20 food bank staff from 16

Table 1. List of Interviewees at Food Banks in the Target States ${ }^{a}$

\begin{tabular}{lcc}
\hline State & $\begin{array}{c}\text { No. of Food Banks } \\
\text { Contacted for } \\
\text { Interview }\end{array}$ & $\begin{array}{c}\text { No. of Staff } \\
\text { Interviewed }\end{array}$ \\
\hline Alabama & 1 & 1 \\
\hline Arkansas & 1 & 2 \\
\hline Florida & 1 & 1 \\
\hline Georgia & 2 & 3 \\
\hline Kentucky & 1 & 1 \\
\hline Louisiana & 1 & 3 \\
\hline Mississippi & 1 & 1 \\
\hline North Carolina & 2 & 1 \\
\hline Oklahoma & 1 & 1 \\
\hline South Carolina & 1 & 2 \\
\hline Tennessee & 1 & 1 \\
\hline Texas & 2 & 20 food bank staff \\
\hline Virginia & 1 & 16 food banks \\
\hline Total & 24 participants. & \\
\hline a Four additional interviews were conducted, as described in the \\
text, for a total of 2
\end{tabular}

Volume 9, Issue 2 / Winter 2019-2020 food banks, one state-level director of produce recovery, and the executive directors and sourcing staff at two of Feeding America's regional aggregators (Table 1). Interviews were conducted by one of the authors over the telephone. Of those interviewed, 15 agreed to be recorded, and these recordings were transcribed verbatim. Detailed notes were taken for those who selected not to be recorded.

Food bank staff were asked to estimate the total pounds of food distributed by their food bank, total pounds of fresh produce distributed, and total pounds of distributed fresh produce that originated at a farm (as opposed to donations from a grocery retailer or produce wholesaler). They were also asked to explain their methods for sourcing from farmers; whether farmers were ever paid and if so, the average price per pound paid; and to reflect on past experiences and future plans for sourcing directly from farmers. Two of the coauthors developed a codebook representing key themes identified to address the research questions, as well as to reflect emergent issues identified by participants (Coffey \& Atkinson, 1996). Codes included, for example, total pounds of produce distributed, types of produce purchased, state funding to purchase produce, health/nutrition, and grower incentives. Once the codebook was developed, two co-authors separately coded one interview and then met to compare their coding and make any needed clarifications to the codebook. One co-author then coded the rest of the interviews using the adjusted codebook. Coding was done manually using Microsoft Word, with separate documents for each code. The co-author also went through each interview to extract the quantifiable data about amounts of produce sourced and amount paid in order to develop the subsequent tables.

\section{Quantitative Findings: How Much and for How Much}

State-specific data is not given in this publication because of IRB specifications that only aggregated or anonymized information would be shared. Specific states are mentioned if the information is available from other public sources. Anonymized estimates per state are given in Table 2.

Across the 13 states, food banks distributed 
1.6 billion pounds ${ }^{1}$ of food, of which 265,630 million were fresh produce. Per-state pounds of fresh produce as a percentage of total pounds of distributed food ranged from $7.6 \%$ to $31 \%$, with an average of $16 \%$. Interviewees reported sourcing fresh produce directly from growers, directly from food banks in other regions, and through the Feeding America Produce Matchmaker program. Respondents were unable to consistently provide a breakdown of pounds from each source.

Fourteen of the 16 food banks in the region reported compensating growers for PPO costs. These 14 were in 11 of the 13 states. In eight of the 11 states, PPO prices were decided from direct conversations with growers during the season, with reported PPO payments ranging from US $\$ 0.08 / \mathrm{lb}$. to US $\$ 0.15 / \mathrm{lb}$., and averaging US $\$ 0.10 / \mathrm{lb}$. Three food banks noted that they used prices that had been determined by other entities. One noted that per-pound benchmark prices were determined with the assistance of university-based economists. The second state stipulates that food banks that receive state funds to support farm-to-food bank transactions should pay growers $95 \%$ of the state's wholesale auction price. The third state (state \#10 in Table 2) has a fund to support farm-to-food bank transactions, and payments paid from that fund must be a minimum of US $\$ 0.10 / \mathrm{lb}$. Once these funds are expended, food banks use negotiated rates. Three state programs provide funding for food banks to purchase produce from farmers: Kentucky's Farm to Food Bank Program, Texans Feeding Texans, and Farmers Feeding Florida.

Five interviewees reported that they had made arrangements with local growers for product in advance of the harvest. One noted a yearly contract with a grower for 300,000 pounds of produce at US $\$ 0.12$ per pound, paying the grower at the time of planting. This type of forward contracting was the exception. In all other cases, informal arrange-

Table 2. Summary of Findings from Interviews with Food Banks in 13 Southern U.S. States, Including Pick and Pack-out Cost (PPO) Compensation from Food Banks to Growers

\begin{tabular}{|c|c|c|c|c|c|c|c|c|}
\hline State & $\begin{array}{l}\text { Total Pounds } \\
\text { Distributed } \\
(000)\end{array}$ & $\begin{array}{l}\text { Pounds of } \\
\text { Produce } \\
\text { Distributed } \\
(000)\end{array}$ & $\begin{array}{l}\% \text { Produce of } \\
\text { Total Pounds } \\
\text { Distributed }\end{array}$ & $\begin{array}{c}\text { Practice of } \\
\text { PPO } \\
\text { Compensation }\end{array}$ & $\begin{array}{l}\text { Pricing: } \\
\text { Negotiated } \\
\text { or Criteria- } \\
\text { based a }\end{array}$ & $\begin{array}{l}\text { Reported } \\
\text { Typical PPO }\end{array}$ & $\begin{array}{c}\text { Has State } \\
\text { Program } \\
\text { to Subsidize } \\
\text { PPO }\end{array}$ & $\begin{array}{l}\text { Ever Done } \\
\text { Forward } \\
\text { Contracting }\end{array}$ \\
\hline 1 & 58,476 & 9,908 & 17 & No & -- & -- & No & No \\
\hline 2 & 54,224 & 5,422 & 10 & Yes & Negotiated & $\$ 0.15$ & No & No \\
\hline 3 & 228,494 & 20,281 & 9 & Yes & Negotiated & $\$ 0.08$ & No & Yes \\
\hline 4 & 141,942 & 30,206 & 21 & Yes & Negotiated & $\$ 0.12$ & No & Yes \\
\hline 5 & 76,647 & 23,996 & 31 & Yes & Criteria & NA & Yes & No \\
\hline 6 & 155,403 & 40,439 & 26 & Yes & Negotiated & $\$ 0.17$ & No & Yes \\
\hline 7 & 75,955 & 20,257 & 27 & Yes & Negotiated & $\$ 0.10$ & No & No \\
\hline 8 & 72,565 & NA & NA & Yes & Negotiated & $\$ 0.10$ & No & Yes \\
\hline 9 & 19,201 & 1,455 & 8 & No & -- & -- & No & No \\
\hline 10 & 450,163 & 48,613 & 11 & Yes & $\begin{array}{l}\text { Criteria \& } \\
\text { Negotiated }\end{array}$ & $\$ 0.10$ & Yes & Yes \\
\hline 11 & 121,000 & 22,000 & 18 & Yes & Negotiated & NA & No & NA \\
\hline 12 & 74,682 & 18,535 & 25 & Yes & Criteria & NA & Yes & No \\
\hline 13 & 91,315 & 24,517 & 27 & Yes & Negotiated & NA & No & No \\
\hline TOTAL & $1,620,070$ & 265,630 & 16 & & & & & \\
\hline
\end{tabular}

a Negotiated pricing refers to prices agreed upon based on discussions between the food bank and the producer. Criteria-based pricing is based on benchmark prices from a designated source (e.g., wholesale auction prices).

$11 \mathrm{lb} .=0.45 \mathrm{~kg}$ 
ments were made between food banks and farmers who had either donated or sold to the food bank in the past, with the food bank agreeing to continue the relationship in the coming season.

\section{Qualitative Findings: Reasons Behind the Practice}

In addition to questions on volume and PPO reimbursement practices, interviewees were asked to reflect on any changes in sourcing practices over time. Most respondents noted that the primary reason for sourcing more fresh produce was the push from stakeholders for food banks to supply healthier foods. Food bank staff noted the availability of new sources of funding that specifically target the purchase of fresh produce, and the need to purchase produce (rather than rely on donations) in order to increase the variety of produce offerings. A number of food bank staff cited the potential "win-win" if this produce could be purchased from local farmers; the purchase could simultaneously support local farm businesses while reducing onfarm waste. From food bank staff and regional aggregators, we also learned of emerging innovative infrastructure models that have formed to meet the distribution challenges of increased demand for fresh, local produce within the food banking system.

\section{Promoting Health}

Food bank staff consistently expressed a commitment to increase the amount and variety of produce that they offer. For example,

Over the last six and a half years I've been here, we've really transformed that program to have more variety and not just if you want produce, sure, here's your potatoes. But we have some of eight different types of produce available at all times ... [We] try to have a variety to really fill the plate of the individual that gets from us. (Interviewee \#1, Production Logistics Manager)

Respondents also noted that donors are interested in linking their monetary donations to healthy foods and that this increased interest from donors in supporting healthy food donations has inspired food banks to actively seek out donors holding these priorities. One operations manager noted, "We now have our development team working on getting donors that are interested in getting people fresh produce" (Interviewee \#5, Operations Manager). A food resource manager echoed this: “There's obviously donors who want to specify where their money goes and produce is one of those things...healthcare providers like $[\mathrm{X}]$ and other hospital companies like nutritious foods to be tied to their donation" (Interviewee \#4).

National-level support and local donations for healthy food were cited by most of the respondents as having created a culture within food banks to procure more produce. The demand for healthy food was expressed as top-down from leadership and bottom-up from partner agencies. For example, one director of procurement cited support from the food bank's board:

It is one of our organizational goals and our strategic goals to distribute fresh, nutritious product, and because that amount of our product just isn't available donated, we do have a budget that's granted by the board to bring in that PPO produce. (Interviewee \#8, Director of Procurement)

A food sourcing manager cited the bottom-up demand they've noticed from the food pantries and other organizations that they serve: "Our agencies are also requesting even more variety of produce" (Interviewee \#3).

\section{Decline in Produce Donations}

A third of the respondents noted that their interest in paying for produce was related in part to a decline in donations from manufacturers and retailers:

In the past, we've really relied on retail donations. As they've dropped, we've definitely increased our produce purchasing. As that trend continues to evolve of donations kind of dropping and us having to rely more on purchased food, produce has been where we make up the difference, so it's increased. It's become increasingly a larger part of our total distribution. (Interviewee \#10, Outreach Coordinator) 
Food bank resource managers perceived these declines in donations as part of companies' desire and ability to track and reduce waste in their supply chains.

Twenty years ago, canning companies wouldn't know their machines made a mistake for two truckloads worth of product or whatever. Now, they can tell when one can is off. There's definitely less canned food donation... fresh produce has a lot of excess, so we're all trying to figure that out. (Interviewee \#1, Production Logistics Manager)

Whereas an increased focus on reducing waste on the national level means that retailers and manufacturers have less excess food to donate, participants identified fresh produce as an opportunity area to reduce food waste while meeting the demands from donors and clients.

\section{Win-win Solution: Supporting Local Farmers}

While food bank staff noted an increased interest in procuring produce more generally, they also made an explicit connection to supporting local farmers. In part, this can be attributed to the priorities of donors from agricultural sectors that include state farm-to-food bank programs:

The thing with those donations [from retailers] are they are very close to the end of their shelf life. They need to go out the same day we receive them or the day after. Pretty quickly they need to go out the door. (Interviewee \#10, Outreach Coordinator)

In addition to these benefits, about onethird of the respondents identified direct purchasing as a win-win that could support farm economic viability. This reasoning demonstrated interviewees' awareness of the challenges that farmers face. For example, a regional warehouse president states, "We want to make it easy for growers to donate produce and not lose their shirt in doing this - they have thin margins and struggle cash-wise" (Interviewee \#12). Another respondent also expressed a desire to support farmers:
There's obviously donors who want to specify where their money goes and produce is one of those things, like there's some Farm Bureau, Farm Credit and farmer co-ops and folks who are tied to the industry, who like to earmark money that they donate for produce procurement. (Interviewee \#4, Sourcing Manager)

Price and quality are also factors that make purchasing fresh produce from farmers appealing, as noted by one director of procurement:

When it comes down to it, produce is much more economical for us because it really is available with that PPO. So the average cost to purchase grocery items is 65 cents a pound. And our average cost on produce is 21 cents a pound. So we can get a lot more produce for our money. (Interviewee \#7, Director of Procurement)

Purchasing, rather than relying on donations, also gives food banks more control over volume and quality. When food banks pay PPO for produce, the product is typically shipped directly from the farm and, therefore, is likely to have a longer shelf life, as one outreach coordinator noted:

[We want to be] a business solution for farmers [to let] them know that we're here for them and that we can handle large volume and that they shouldn't be afraid to reach out even if they think it's too much or maybe that it's something that we can't use. (Interviewee \#4, Food Resource Manager)

At the same time, study participants said that they often used the mission of the food bank as a starting place to recruit growers, appealing to farmers' charitable inclinations and desire to reduce waste, while also helping them see the benefits of selling fresh produce at PPO rates.

\section{Infrastructure Taken to a New Level}

Tapping into the excess produce on farms requires appropriate storage and distribution equipment and practices. Individual food banks have added cool- 
ers and refrigerated trucks for the storage and delivery of fresh produce for their clients. Food banks with excess produce can post that excess on Feeding America's Produce Matchmaker platform or make direct arrangements with food banks in other states, thus moving produce from areas with a surplus to those in need. As one food bank sourcing manager describes, the Produce Matchmaker platform allows both "real-time and forward planning" for food bank produce needs; growers and others can post planned supplies and the surplus they expect in the coming season, and food banks can lock in those future supplies.

As noted above, Feeding America has also developed six regional distribution centers for the aggregation and distribution of fresh produce. The centers provide a number of efficiency benefits to network members, as one regional warehouse president explains:

Any single food bank can usually not take that much produce. We are trying, as a nonprofit, to be an aggregator-we are working with 40 different food banks across [X] states. [What] we offer to growers is that when they have an excess amount of produce, they can let us know, and depending on commodity, PPO cost, [we] can commit to moving it for them and get it distributed through our network of different food banks, and thus we can handle large amounts of produce at any given time. (Interviewee \#12, Regional Warehouse President)

\section{Study Limitations}

This research does not represent an exhaustive study of the food bank landscape in the southeastern U.S. Reliable state-level totals of pounds distributed, pounds of produce, etc., were not available for all states. Additionally, while we sought to determine the proportion of fresh produce sourced directly from growers compared to other sources, most food banks could not separate produce sourced by category. Thus, the quantitative findings presented in this paper reflect an effort to capture the best available estimates. Our findings also do not reflect food banks that operate outside the Feeding America network in these states. In addition, the findings do not reflect produce sourcing and purchasing that occurs directly between individual local pantries and local growers.

\section{Summary and Directions for Future Research}

Historically, the food bank system has relied largely on retail and manufacturing donations of shelfstable products. The system's initial emphasis on calories and volume has more recently given way to a focus on the inclusion of fresh foods, including fresh produce (Campbell et al., 2015). As more food banks shift their priorities and capacity to fresh produce, regional warehouses have emerged to absorb larger quantities and redistribute them across an entire network of food banks. The continuing push for fresh and locally produced foods, combined with declines in retail and manufacturing donations of canned foods (Campbell, Ross, \& Webb, 2013), presents a potential opportunity to divert current produce losses that are occurring onfarm in a way that also benefits growers. This study confirms that the practice of paying growers in the form of "pick and pack-out costs" is common across states in the southeastern region of the U.S. Based on informant interviewees and investments by donors and Feeding America, the practice of paying farmers for produce is likely to grow.

Our findings thus suggest that food banks are a potentially reliable sales channel for produce growers. Given that PPO prices are generally much lower than market prices, this channel should be seen as one part of an overall marketing strategy. Sales to food banks are a way for growers to make use of surplus produce or items not meeting market standards because of characteristics such as shape, size, and color. This strategy can reduce waste in terms of the actual product that would otherwise go unharvested, the investment in natural resources (e.g., water, land), and added production inputs invested by the grower. Based on the findings from this study and others (Dunning et al., 2019; Vitiello et al., 2015), food system practitioners should include food banks as a potential market for the farmers with whom they work, and should seek to build relationships between these two parts of the food system.

Interviews with management at two regional 
cooperatives highlight the role of regional aggregation, in the form of nonprofits designed specifically to serve food banks, for sourcing of fresh produce. These aggregators can provide key system benefits to the food bank network. They can break down truckloads and pallet loads of produce into mixed loads for delivery to food banks that do not have the capacity to receive and distribute large volumes. The co-ops can also smooth out regional supply and demand by moving surplus products in one area to areas with deficits. By providing a centralized point of aggregation and distribution, the coops can also enable food banks to make regular orders of an array of produce items. Food banks can then keep their inventory stocked with more variety and more consistency, thus benefitting their client organizations. The co-op operations are financed by fees charged to food banks per pound of delivered product. Having this infrastructure operating at a large scale takes the system one step further in its ability to capture the excess product that is often lost at the farm level. Logistical, operational, and economic analysis of this system is an important direction for future research (see Foundation for Food and Agriculture Research, 2019).

While this study provides a snapshot of the potential market opportunities for growers in the food banking system, there are several important areas that remain for future research. Longitudinal case studies that include the economic outcomes for growers who have sold to food banks could help confirm the viability of this market from the growers' standpoint. A comparison of the use of the Produce Matchmaker platform as an alternative or supplement to food bank regional distribution centers would also be insightful. Quantitative analysis of the platform as a means to forward contract with growers, as well as a consideration of alternative ways to operate the platform, would be valuable. For example, prices of available produce on the platform do not change over time, and thus do not reflect their shelf life, and the price of a product posted for a future season does not change as the season approaches (and, presumably, the offering grower might be incentivized to lower the price).

Several interviewees also expressed concern that the practice of paying farmers might lead to a decline in grower donations. This led some food bank staff to use the term "compensation" rather than "payments" when referring to PPOs, as well as a stated preference to not openly advertise that the practice was used. While this was not a widely shared sentiment among the interviewees in our study, it points to the potential implications of the shifting practices and missions of food banks, and thus merits attention in future studies. Investigation of the impact of state-level programs that encourage farm-to-food bank relationships could also inform the development of public policy that simultaneously addresses food insecurity, farm viability, and food loss.

\section{References}

Bazerghi, C., McKay, F. H., \& Dunn, M. (2016). The role of food banks in addressing food insecurity: A systematic review. Journal of Community Health, 41(4), 732-740. https://doi.org/10.1007/s10900-015-0147-5

Campbell, E. C., Ross, M., \& Webb, K. L. (2013). Improving the nutritional quality of emergency food: A study of food bank organizational culture, capacity, and practices. Journal of Hunger \& Environmental Nutrition, 8(3), 261-280. https://doi.org/10.1080/19320248.2013.816991

Campbell, E., Webb, K., Ross, M., Crawford, P., Hudson, H., \& Hecht, K. (2015). Nutrition-focused food banking (NAM Perspectives Discussion Paper). Washington, D.C.: National Academy of Medicine. https://doi.org/10.31478/201504a

Coffey, A., \& Atkinson, P. (1996). Concepts and coding. In A. Coffey \& P. Atkinson, Making sense of qualitative data: Complementary research strategies (pp. 26-53). Thousand Oaks, CA: SAGE.

Dunning, R. D., Johnson, L. K., \& Boys, K. A. (2019). Putting dollars to waste: Estimating the value of on-farm food loss. Choices, Quarter 1. Retrieved from http://www.choicesmagazine.org/choices-magazine/themearticles/examining-food-loss-and-food-waste-in-the-united-states/putting-dollars-to-waste-estimating-the-value-ofon-farm-food-loss 
Elejalde-Ruiz, A. (2019, January 22). Federal employees turn to food pantries during government shutdown: 'After a while you have to let that pride go.' Chicago Tribune. Retrieved from https://www.chicagotribune.com/business/ct-biz-government-shutdown-food-pantries-20190122-story.html

Feeding America. (2017, August 28). Establishment of six regional produce cooperatives [Press release]. Retrieved from https://www.feedingamerica.org/about-us/press-room/produce-cooperatives

Feeding America. (2018). 2018 annual report. Retrieved from https://www.feedingamerica.org/sites/default/files/201812/2018\%20Feeding\%20America \%20Annual\%20Report 0.pdf

Foundation for Food and Agriculture Research. (2019, April 9). FFAR awards \$1 million grant to reduce food insecurity [Press release]. Retrieved from https://foundationfar.org/2019/04/09/ffar-awards-1-million-grant-to-reduce-food-insecurity/

Johnson, L. K., \& Dunning, R. D. (2020). Food loss on the farm: Lessons learned from conversations with produce growers. In T. Minor, S. Thornsbury, \& A. K. Mishra, \& (Eds.), The economics of food loss in the produce industry (pp. 116-130). New York: Routledge.

Johnson, L. K., Bloom, J. D., Dunning, R. D., Gunter, C. C., Boyette, M. D., \& Creamer, N. G. (2019). Farmer harvest decisions and vegetable loss in primary production. Agricultural Systems, 176, Art. 102672. https://doi.org/10.1016/j.agsy.2019.102672

Johnson, L. K., Dunning, R. D., Bloom, J. D., Gunter, C. C., Boyette, M. D., \& Creamer, N. G. (2018). Estimating onfarm food loss at the field level: A methodology and applied case study on a North Carolina farm. Resources, Conservation \& Recycling, 137, 243-250. https://doi.org/10.1016/i.resconrec.2018.05.017

Johnson, L. K., Dunning, R. D., Gunter, C. C., Bloom, J. D., Boyette, M. D., \& Creamer, N. G. (2018). Field measurement in vegetable crops indicates need for reevaluation of on-farm food loss estimates in North America. Agricultural Systems, 167, 136-142. https://doi.org/10.1016/j.agsy.2018.09.008

Poppendieck, J. (1999). Sweet charity?: Emergency food and the end of entitlement. New York, NY: Penguin.

Shimada, T., Ross, M., Campbell, E. C., \& Webb, K. L. (2013). A model to drive research-based policy change: Improving the nutritional quality of emergency food. Journal of Hunger \& Environmental Nutrition, 8(3), 281-293. https://doi.org/10.1080/19320248.2013.821963

Simon, D. (2019, January 20). Federal employees turn to food banks to feed their families during shutdown. CNN. Retrieved from https://www.cnn.com/2019/01/17/us/government-employees-shutdown-food-banks/index.html

Vitiello, D., Grisso, J. A., Whiteside, K. L., \& Fischman, R. (2015). From commodity surplus to food justice: Food banks and local agriculture in the United States. Agriculture and Human Values, 32(3), 419-430.

https://doi.org/10.1007/s10460-014-9563-x 